\title{
ADOPTION OF CIRCULAR ECONOMY FOR A SUSTAINABLE SOLID WASTE MANAGEMENT SYSTEM IN MALAYSIA
}

\author{
*MOHD SAIFUL ANUAR ZAINAL \\ ZAKARIA ABAS \\ Othman Yeop Abdullah Graduate School of Business (OYAGSB) \\ Universiti Utara Malaysia \\ *Corresponding Author: mhd_saiful@oyagsb.uum.edu.my; \\ saifulanuar@e-idaman.com;
}

\begin{abstract}
The purposes of this study are to address the current solid waste management (SWM) issues and to evaluate the best available practices that can be adopted to develop a holistic, integrated, effective and a sustainable SWM system in Malaysia. The idea is to analyze and to evaluate the weaknesses of the current practice of "extract-make-use-dispose" linear economic (LE) model that causes depletion of natural resources, massive increase in the generation of solid waste, severe degradation of the environment and a substantial cost to manage. These results will be synthesized to establish critical gaps to benchmark against the new economic model of a circular economy (CE) that works on a closed-loop system of reducing, reuse and recycle (3R). CE aims to efficiently utilize the resources to allow for maximum reuse through refurbishment, remanufacturing and recycling which will minimize the wastages for disposal. This study employs a literature review to identify relevant practices of a circular business model that can potentially be adopted, a life-cycle (LC) analysis to assess the environmental impacts and a study on waste characteristic and its composition to determine the waste fraction and the amount of energy contained in the solid waste. This paper gives an insight into the possibility of embracing the concept of a CE alongside with a suitable treatment and disposal technologies to develop a sustainable SWM system in Malaysia. This holistic approach would able to minimize the waste through waste prevention, to maximize the economic return through reuse, recycle and recovery, to give the protection to the environment and to improve the quality of life.
\end{abstract}

Keywords: Circular economy, 3R principle, Solid waste management, Sustainable development

Received: $14 / 2 / 2018$

Revised: 12/4/2018

\section{Introduction}

Solid waste management (SWM) is one of the most challenging issues faced by many developing countries around the world. The economic development that has a positive correlation to the population and urbanization is the primary causal factor contributing to the issues (Manaf, Samah, \& Zukki, 2009). It promotes population growth and rural-urban migration which improve the financial wealth and disposable income that influence the increase
Accepted: 7/8/2018

Published: 14/7/2019 in the consumption of goods and services. This phenomenon has led to the exponential growth in the solid waste generation per capita (kg/capita/ day) of 2.13 and 0.60 currently to approximately 2.40 and 0.80 in 2025 for the high-income and low-income countries respectively. The worldwide solid waste generation is expected to reach nearly 3.96 billion tons in 2025 whereby 2.20 billion tons are the amount contributed by the world cities (Hoornweg \& Bhada-Tata, 2012). The waste generation rates for the lowerincome countries would be more than double over the next 25 years (Karak, Bhagat, \& 
Bhattacharyya, 2012). It is alarming to note that the SWM also forecasted a significant financial impact globally at the cost of US dollars (USD) 205.4 billion currently to about USD375.5 billion in 2025 (Hoornweg \& Bhada-Tata, 2012), and it will be more severe in low and middle-income countries.

Therefore, in the absence of a sustainable SWM system in place, the world's population will generate a massive amount of solid waste to be discarded and disposed of without treatment and recovery. These practices will cause severe pollution to the environment, health and sanitation problems that are detrimental to the quality of life (Badgie, Samah, Manaf, \& Muda, 2012). The failures of many SWM systems are mainly due to the imbalance between the rising generation of the solid waste amounts over the recovered, treated and the disposal quantity. For past decades, the SWM issue continued to be a significant environmental, economic and social issues that need urgent attention from all level of societies. Good decision-making on SWM that would holistically address topics on the current practices on waste generators and the application of suitable technologies for treatment, recovery, and disposals is the most significant contributions to achieve sustainability. This aspiration can be attainable through:

i. The transformation from the current practice of a linear economy (LE) to a circular economy (CE) that will efficiently utilize the resources through the application of reducing, reuse and recycle (3R). CE practices will maximize the resource utilization and minimize the waste generation amount,

ii. The use of suitable technology to treat, recover and disposal of solid waste that can reduce the adverse impact on the environment, maximize the economic return and provide livable cities for the society.

This approach addresses the objective of sustainable development (SD) that emphasizes waste cannot be discarded or disposed of and should be recovered and treated as a valuable resource. The Bruntland Commission (1987) defined sustainability as a development that meets the needs of the present without compromising the ability of future generations to meet their own needs (Emas, 2015). On this regard, CE practices have been proven to solve more than half of the high-level Sustainable Development Goals (SDG) within the Post-2015 Development Agenda through the recycling practices especially on the responsible consumption of products and services (Waste, 2015). CE is an economic strategy that applies the circular business model, and it is regenerative by design that works on a closed-loop system of $3 \mathrm{R}$ that aims to efficiently utilize the resources to allow for maximum reuse through refurbishment, remanufacturing and recycling (WBCSD, 2016). Transitioning to the $\mathrm{CE}$ will catalyze the most transformational economic, social and environmental changes and will pave a way towards sustainability.

This paper identifies the weaknesses of the existing SWM system and proposes the adoption of relevance $\mathrm{CE}$ practices alongside with reliable technology in treatment, recovery, and disposal for the development of the sustainable SWM system in Malaysia. In the context of SWM system, Scott (2015) defined CE as "a concept used to describe a zero-waste industrial economy that profits from two types of material inputs. The inputs include (1) the biological materials that can produce valuable byproducts and returned into the biosphere in a restorative manner; (2) the technical elements that can be recycled to optimize its utilization. Other schools of thought on the CE are Regenerative Design, Performance Economy, Cradle to Cradle, Industrial Symbiosis, Industrial Ecology, Biomimicry, Blue Economy, Natural Capitalism and Industrial Metabolism. Lewandowski (2016) described those schools of thought are complementing each other and provided the foundation for the main principles of this new approach to the economy which includes (1) design out waste/ design for reuse; (2) build resilience through diversity; (3) rely on energy from renewable source; (4) think in systems; and (5) share values (symbiosis). 
The remaining of the paper will be organized as follows. It provides the related review of the literature, the theoretical and conceptual frameworks and research method for the study. The anticipated findings and its significance to the government aspiration for sustainable development initiatives achievement comes next. This paper provides a proposition stem out from the study that is found in the conclusion section.

\section{Literature Review}

This section contains three subsections. It begins with the presentation of the concept of $\mathrm{CE}$ as an economic strategy to promote sustainable development. Zero waste theory (ZWT) for resource efficiency (RE) is presented next and followed by Malaysia SWM scenario.

\section{Circular Economy}

The massive increase in solid waste generation, climate change and pollutions, depletion of natural resources, public health and sanitation problems and substantial cost to manage SWM signified that the current practice of an LE is not sustainable (International Solid Waste Association, 2015). In contrary, the adoption of a CE business model will capture significant benefits which include economic growth, cost reduction, reduced energy consumption and carbon dioxide $(\mathrm{CO} 2)$ emissions and increased the supply chain and resource security (WBCSD, 2016). International Solid Waste Association (ISWA) describes that the LE practices (Figure 1 caused $80-90 \%$ of what is used by the consumers becomes waste within six (6) months, and about $20 \%$ of global material extraction become waste each year. ISWA also reported that the generation of solid waste would rise by $0.69 \%$ for every $1 \%$ increase in the national income in the Organization for Economic Co-operation and Development (OECD) countries (ISWA, 2015). Transitioning to the CE will provide an opportunity to reap the global Gross Domestic Product (GDP) growth of USD4.5 trillion by 2030 (WBCSD, 2016).

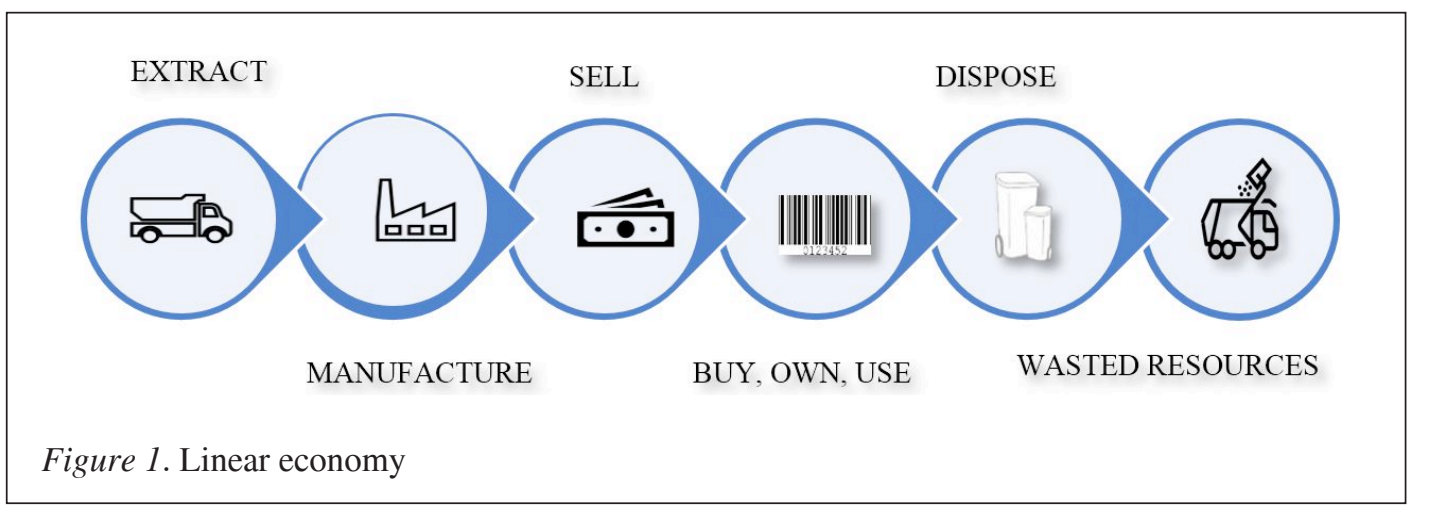

Therefore, many developed countries have switched from the current LE model to a new system of Resource Management (RM) within a CE. CE has emerged as an economic strategy rather than a purely environmental strategy with the primary objectives, which are to promote the SD of economy and society and to achieve sustainable environmental protection. Under this model, the SWM is focusing primarily on an upstream oriented to address the waste problem at its source and to efficiently utilize the resources as compared to the initial focus on the discarded waste in the early 1960s (Waste, 2015). These CE practices will ensure that the resources are used with higher efficiency, reused and recycled wherever possible to minimize pollution, reduce costs and wastages. Boulding (1966) defined a CE as a closed economic system that harmonizes the economy and the environment, by a circular relationship (Figure 2 - Model of Circular Economy). 


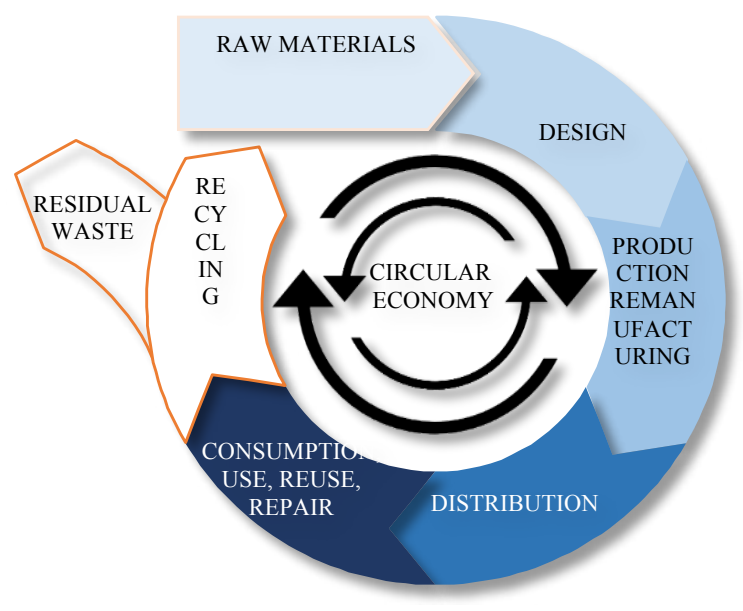

Figure 2. EU model of circular economy

It involves the transformation of industrial organization, urban infrastructure, environmental protection, technological paradigms, policies and legislation, and the social welfare distributions. Switching to CE would not only bring savings of hundreds of billions of USD to the European Union (EU) alone, but it will significantly reduce the negative impact on the natural environment (Ellen MacArthur Foundation, 2013). As an effective means of $\mathrm{SD}, \mathrm{CE}$ is proven to harmonize the economy, environment and the societies in many developed countries like Sweden, Germany, Japan, and China. Therefore, CE has obtained the attention of many academics and the government as one of the most substantial moves towards sustainability. CE practices can help to achieve the Paris Climate Agreement and the United Nation (UN) SDG.

\section{Zero Waste Theory for Resource Efficiency}

Zero waste theory (ZWT) is the main thrust of a $\mathrm{CE}$ development with the waste management hierarchy (WMH) that forms the basis for the emergence of a CE to achieve Resource Efficiency (RE). This approach will lead to a green economy and sustainability. The WMH classifies SWM strategies according to their desirability regarding waste minimization(Figure
3 -with the aim to maximize the practical benefits from products and to minimize the generation amount of solid waste. Source reduction is the most preferred option according to the waste management strategy (Johari, Alkali, Hashim, Ahmed, \& Mat, 2014). The WMH concept represented as a pyramid to allow for the policy intervention to prevent and to reduce the waste generation, followed by the recovery process before the disposal of residual waste to disposal facilities. The WMH represents the latter parts of the life-cycle (LC) for each product that begins with design, manufacture, distribution, use and then followed through the waste hierarchy's stages of reuse, recycling, recovery, and disposal. Each of the above steps of the LC offers opportunities for policy intervention, product revision and redesign to minimize waste potential and to maximize its utilization.

$\mathrm{RE}$ reflects the understanding that current economic growth and development will not sustain with the current production and consumption patterns. RE is the focal point of $\mathrm{RM}$ with the aim to reduce the environmental impact of the production and consumption of goods, from the raw material extraction to the last use and disposal. This process of RE can 
address sustainability with an opportunity to reap a range of benefits and is becoming an essential driver for economic success in a world where resources are scarce and finite.

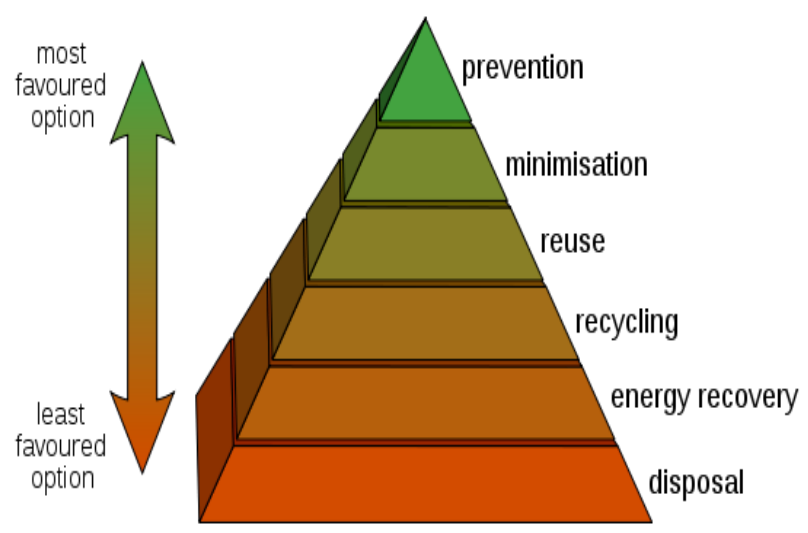

Figure 3. Waste minimization hierarchy

CE derives the following benefits towards sustainability which include:

i. Reducing adverse impacts on the environment through the application of the $3 \mathrm{R}$ principle and minimizing resource extraction,

ii. Improving economic efficiency through maximization of resources utilization, potential economic benefit from renewable energy and secondary raw materials,

iii. Reducing adverse impacts on health through implementation of good SWM practices which lead to more appealing settlements and conducive environment for a better living,

iv. To provide a more robust economy and more inclusive society for the next generations.

In fact, SWM shall have a common goal to improve the quality of life. At present, many developing countries are still struggling to establish their basic SWM system stemming from too many limitations, amongst others are due to the societal reluctant to change from the current LE practices, lack of funds, technology and expertise. Overcoming this challenge will be more difficult with the forecasted increase in population over the next 20 years which lead to the significant increase in waste generation (Waste, 2015).

\section{Malaysia SWM Scenario}

Malaysia with 31.9 million populations and $1.8 \%$ population growth faces similar problems due to its limitations to cope with the everincreasing rate of solid waste generation. The generation of solid waste in Malaysia has increased by more than $91 \%$ over the past ten (10) years due to the rapid development of urban cities, rural-urban migration, increase in per capita income, and the change in consumption patterns (Periathamby, Hamid, \& Khidzir, 2009; Johari et al., 2014). Performance Management and Delivery Unit (2015) under the Prime Minister Department projected that the average increase in waste generation rate is $5.2 \%$ from 2015 to 2020 (Figure 4). From the total amount of solid waste generated in 2016, the household sector contributed $65 \%$ followed by commercial and institutional $28 \%$ and industry $7 \%$. The 
composition of waste for a household being the largest generator is $45 \%$ organic, $13 \%$ plastic, $9 \%$ paper, $6 \%$ garden waste, $12 \%$ diapers and $16 \%$ other residuals (Figure 5 ). The government spending would increase exponentially at a rate of $26 \%$ per annum with Ringgit Malaysia (RM) 2.38 billion spent in 2016 to manage the SWM.

The projection made by the Performance Management and Delivery Unit (PEMANDU) was slightly higher as compared to the actual data presented by Ybhg. Dato'Sri Hj Mohammad bin Mentek, the Secretary-General of Ministry of Urban Well-being, Housing and Local Government (MHLG) of Malaysia at ISWA World Congress on 25 $5^{\text {th }}$ September 2017 in Baltimore, the United States of America (USA). The actual data indicated that the Malaysian peoples generated 37,000 tons per day of solid waste in 2016 with a growth rate of $4 \%$ and a recycling rate of $21 \%$ while the remaining residual waste ended up at disposal sites which majorities are dumpsites. The waste generation per capita has been significantly increased over the years from 0.8 in 2005 to 1.17 in 2016 (Mohammad, 2017). Perbadanan Pengurusan Sisa Pepejal Dan Pembersihan Awam (PPSPPA) reported that the department operational cost had increased at an average of $39.4 \%$ per annum from 2012 to 2016 and $87 \%$ allocation spent on SWM. In 2016, the government spent in a total of RM1.86 billion on SWM with RM74 million paid for the operation and maintenance of the disposal facilities (Perbadanan Pengurusan Sisa Pepejal Dan Pembersihan Awam, 2016). The SWM cost that had over the years has reached a stage beyond the government's financial capability. The trend could be the results of changes in consumption habits as well as the increasing affordability of consumer goods (Periathamby, Hamid, \& Khidzir, 2009). Even though the actual data is reported lower than the projection, the situations are still very alarming Figure 4-(Source: PEMANDU. 2015

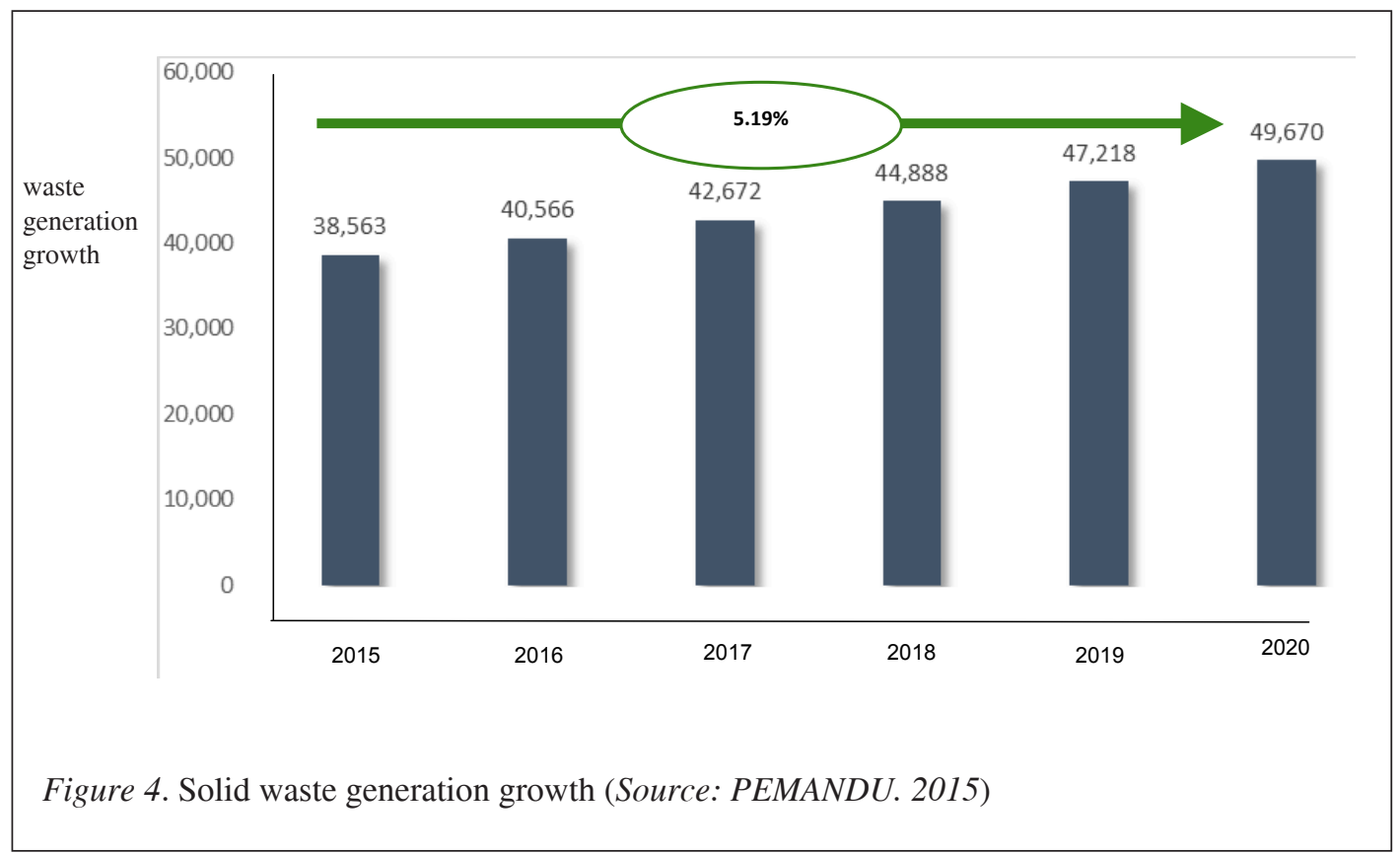


Solid waste generation in Malaysia (2016) Household waste composition, as generated (2016)
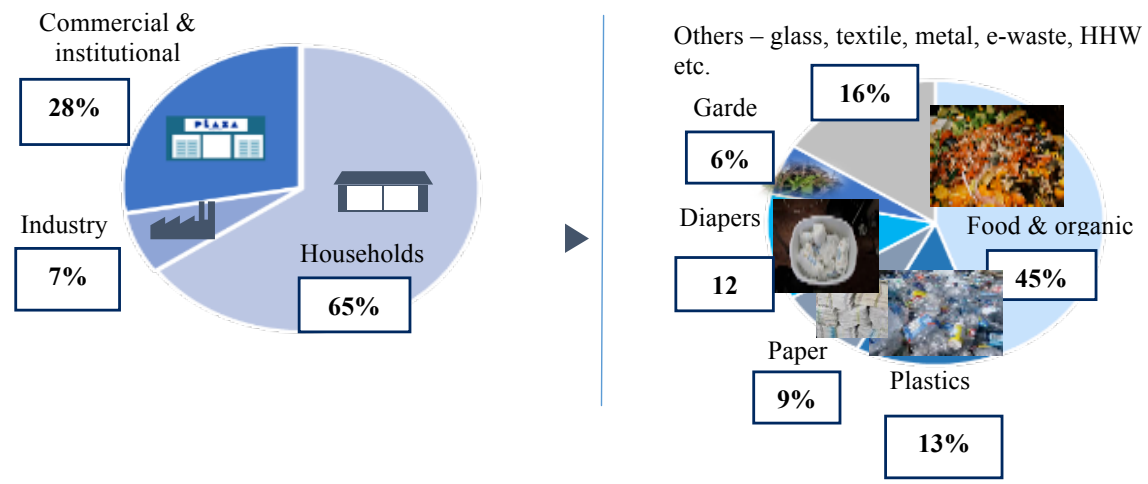

Figure 5. Solid waste composition growth (Source: PEMANDU. 2015)

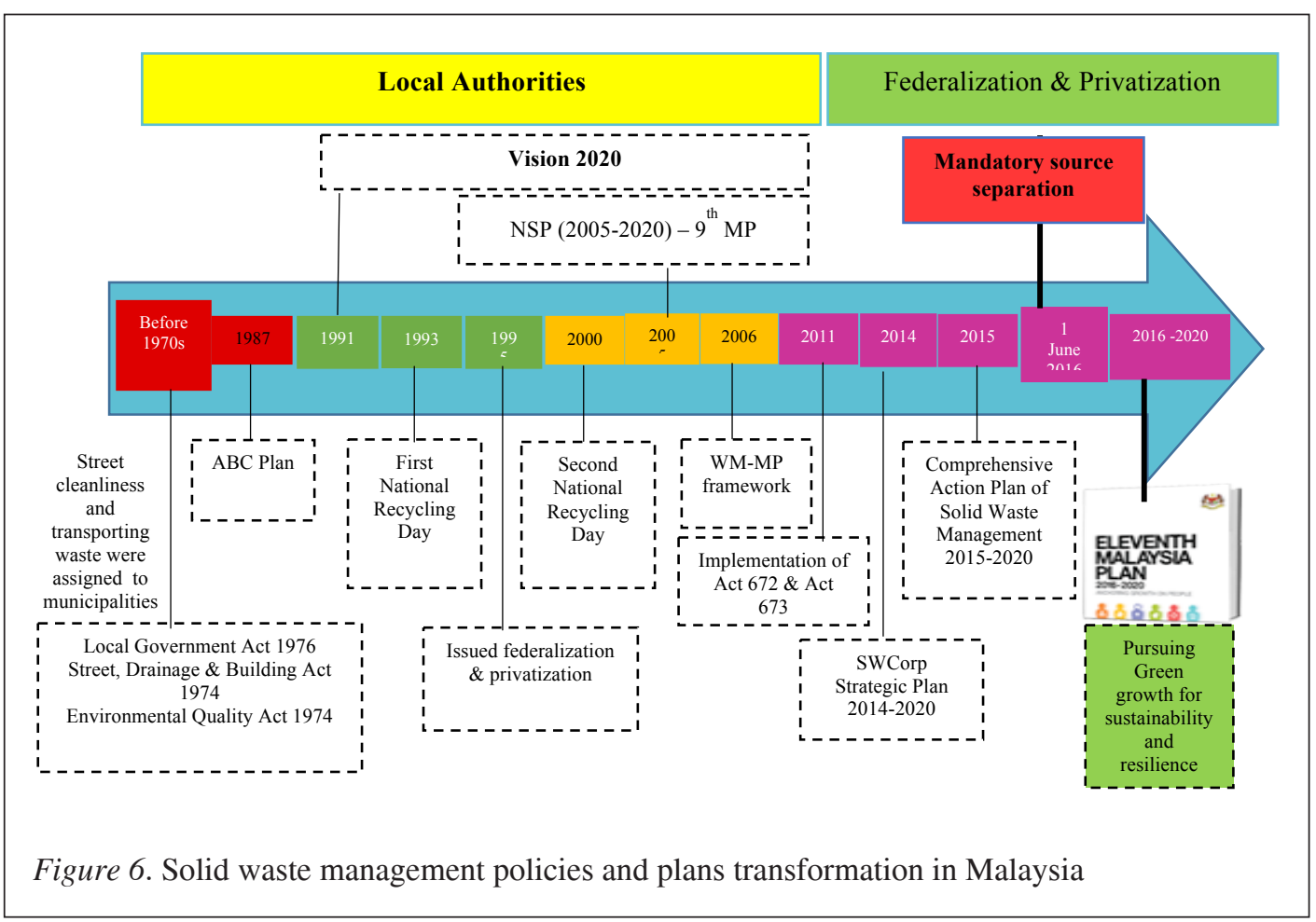

Malaysia has taken several initiatives to cope with these issues from the implementation of the national action plan known as Action Plan for a Beautiful and Clean Malaysia in 1988 to the recent Enactment of Solid Waste Management and Public Cleansing Act (Act 672) in
September 2011. Figure 6 illustrates the overall transformation plan in Solid Waste Management Policies and Plans Transformation in Malaysia (Moh \& Abd Manaf, 2017). The Enactment of Act 672 together with the privatization to the three (3) appointed concessionaires has brought massive 
transformation in lifting up the service quality of the SWM in Malaysia. The primary objective of the Act 672 is to standardize the level of SWM services across all local authorities regardless of their respective income levels (Solid Waste Management and Public Cleansing Act, 2011). Under this Act, the federal government will manage the overall SWM system. The National Solid Waste Management Policy was endorsed with two (2) goals:

i. To generate a holistic SWM system with fullintegration, cost-effective, sustainable, andacceptable to the community,emphasis on the environmental conservation and technology selection which are affordable and assure public health,

ii. To implement the SWM system based on the WMH that gives priority to waste reduction through $3 \mathrm{R}$, intermediate treatment, and disposal.

Despite several initiatives to cope with these issues, Malaysia is still unable to transform the overall landscape towards sustainable SWM practices. The main problems are related to the lack of public's awareness and their resistance to change, lack of political drive to enforce on related policies, funding, technology, and markets creations to adapt to the SD approaches (Moh \& Abd Manaf, 2014; Performance Management and Delivery Unit, 2015). Absences of proper enforcement to the existing waste legislation across all sectors of society have caused the policy to fail to achieve their desired intended purposes and created an ignorant Malaysian society towards the importance of building sustainable living (Badgie et al., 2012). As reported by SWCorp, the government program on the mandatory separation at the source (SAS) which took effect on June 2016 did not bring significant impact in the waste generation pattern. Therefore, this study proposes to adopt the concept of a CE from a successfully developed country like Sweden and Japan to fast-track the development of a sustainable SWM in Malaysia. The idea brings new growth and job opportunities, and it was formed from the recognition that an LE is not sustainable (International Solid Waste Association, 2015). It is vital to ensure that every product produced with the waste prevention in mind and each ton of solid waste should go through the process for reuse, recycle and treatment with suitable technology before disposal at safely engineered landfills.

Hence, this paper gives an insight into the possibility of embracing the concept of a $\mathrm{CE}$ and further establish a proposed framework and enable to suit Malaysian's needs towards developing a sustainable SWM in the country. Findings from the study endeavor to provide guidelines for Malaysia to realize a successful transformation towards a $\mathrm{CE}$ that will minimize the wastages, maximize the economic return from solid waste, reduce the cost, protect the environment and improve the quality of life. The change will pave the way for a more realistic roadmap towards sustainability. The scope of the study will emphasize the household solid waste, focusing on the food waste and recyclable materials. The study will provide evidence on the importance of the government's political will to engage, communicate and execute relevant policies, establish collaboration and inculcate the $3 \mathrm{R}$ culture among all stakeholders, develop the secondary raw material's market and provide funding to realize a successful adoption of a CE. It will also provide valuable information in term of waste composition and characteristic, required legislation framework, policies and the infrastructures necessary to achieve sustainability. The data can be used to identify suitable treatment and disposal technologies, and for further research to replicate into other areas of study.

\section{Theoretical and Conceptual Frameworks}

SWM has positioned itself as an entry point for SD which directly links to a range of global challenges such as health, climate change, 
poverty reduction, food and resource security and sustainable production and consumption (Waste, 2015). Therefore, many past studies on SWM applied to SD framework. A study by the United Nations Environment Program (UNEP) as published under the Waste (2015) indicated that solving SWM problems will help to address more than half of the high-level SDG within the Post-2015 Development Agenda and promises significant early reductions in greenhouse gaseous (GHG) emissions throughout the economy. Schroeder (2018) indicated that among the primary goals of SDG that are related to SWM are (1) to provide affordable solid waste collection services for all areas by 2020; (2) to eliminate uncontrolled dumping and open burning by 2020; (3) to ensure sustainable SWM, particularly hazardous waste by 2030; (4) to substantially reduce the solid waste generation through the adoption of the CE.

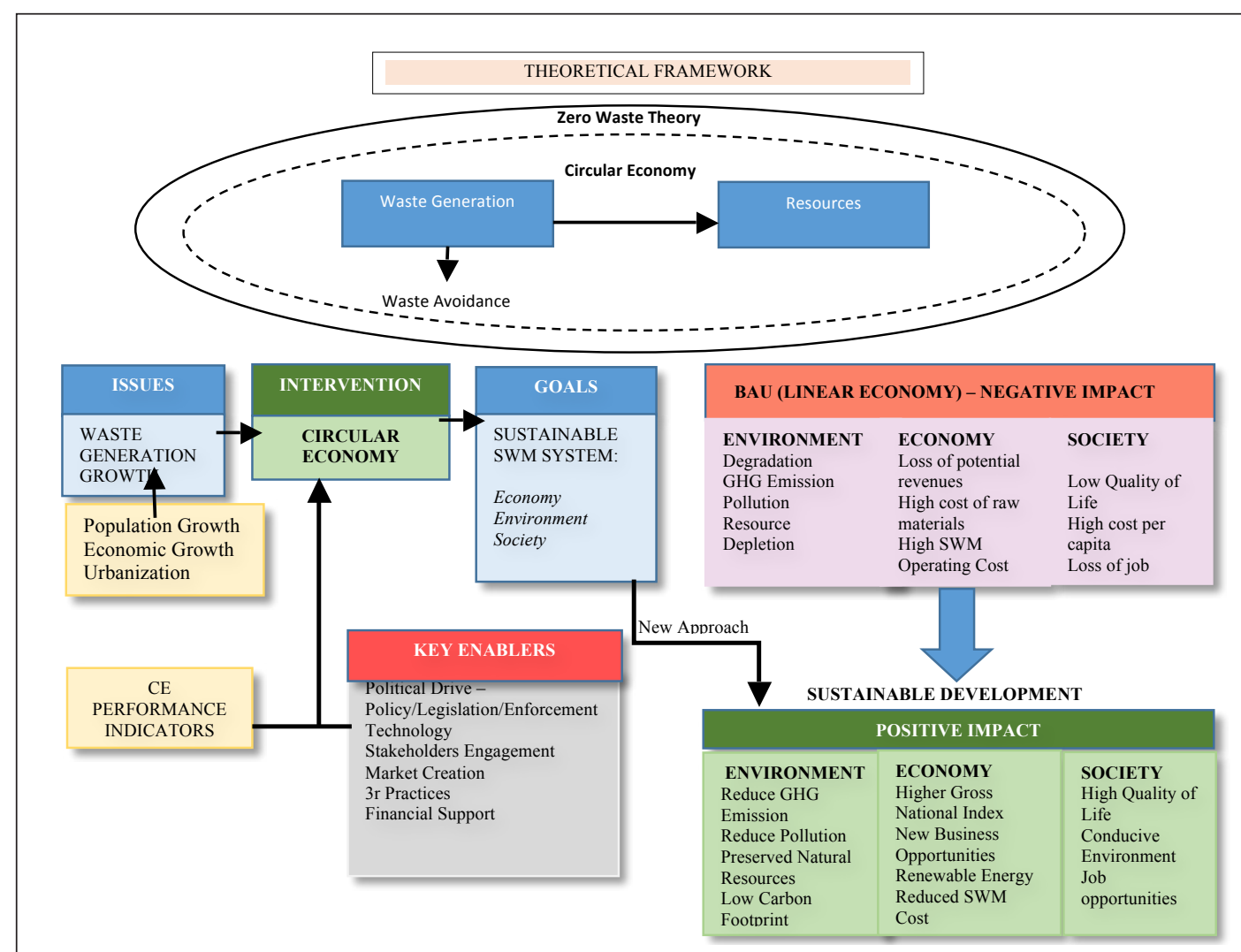

Figure 7 . Theoretical and conceptual frameworks

This study proves that SWM is well embedded within the SDG to harmonize the environment, economy, and society as well as to the intergenerational equity. SWM industry also sits at the center of the transformation with the ability to work with both industry and policymakers to shift the balance between the primary and secondary raw materials. This study will emphasize towards the adoption of a CE that underlines waste prevention as opposed to endof-pipe waste management and to treat waste as valuable resources. The following theoretical and conceptual frameworks including five core research questions (RQ) will guide the study (Figure 7). 
i. $\quad$ RQ1 - Does economic development influences population and urbanization to increase the solid waste generation amount?

ii. RQ2 - Does the increase in waste generation increased SWM cost?

iii. $\quad$ RQ3 - Do political drive, education and the public's attitude, policy adjustment and enforcement influence the current LE practice and the transformation towards a CE?

iv. RQ4 - How much economic benefits that we can derive from solid waste? Can the amount alleviate the current government financial burden?

v. RQ5- How can a CE intervene in the current SWM practice to achieve sustainability? How solid waste treatment and disposal technologies contribute to the success?

The transformation of the SWM concept of an LE to a CE is an important step to achieve an effective, sustainable SWM system (International Solid Waste Association, 2015). $\mathrm{CE}$ aims to decouple economic growth from the limited resource consumption, environmental degradation and waste generation. CE falls back against the ZWT and relies on three (3) principles, which are (1) design out waste and pollution; (2) keep products, components and materials at their highest value in use; and (3) regenerate natural systems (Ellen MacArthur Foundation, 2013). The successful implementation of CE will (1) relieve pressures on municipal service and budgets; (2) increase disposable incomes; (3) encourage an innovation-rich economy; (4) protect the environment; (5) improve the quality of life; and (6) increase employment opportunities. The EU model of CE had outlined four key drivers which include (1) legislation; (2) commodity price and raw material; (3) business drivers and; (4) green taxation.

For Malaysia to embrace to this change towards a CE, the country needs to develop a comprehensive and holistic transformation that cover all aspects including most importantly the structural and policy adjustments, political will, public attitude and behavioral change to ensure smooth and successful transformation. Malaysia needs to fill in the gaps following the successful implementation of CE by the developed countries. The recent enactment of Act 672 mainly focusses on the solid waste collection and public cleansing activities, with little attention addressing the waste avoidance, reduction, reuse, recycle and recovery. The Act only touch base on the enforcement of separation at source, buyback and deposit refund system which is still far from achieving its full objectives (Solid Waste and Public Cleansing Management Act, 2011).

Following the EU model, it is time for the country to relook at the applicable policies like extended producer responsibility (EPR), pay as you throw (PAYT) principle and a tax incentive for green projects. The government needs to seriously enforce on the SAS, landfill tax, limit the amount of imported secondary raw materials and increase the primary raw material's cost as well as to support the utilization of renewable energy produced from solid waste. The government has to create a market for the secondary raw material and to make it viable for the private investment and to ensure full financial support from the financial institutions. Also, the government needs to strengthen the communication, engagement, education, and enforcement on the importance of sustainable SWM system to be ingrained in every level of societies and to build as everyone's culture.

After five years of the execution and enforcement of the Act 672 and full privatization of the SWM system, the concept is proven to be efficient and effective with tremendous reduction of complaints (87\%) from public from 2011 to 2015, increased in recycling rate from $5.5 \%$ in 2007 to 21\% in 2016 (Perbadanan Pengurusan Sisa Pepejal Dan Pembersihan Awam, 2016). The privatization has also succeeded in 
delivering effective and efficient services where more than $90 \%$ of waste generated have been able to be collected, transported and disposed at landfills as compared to $76 \%$ on previous years. Nevertheless, the availability of proper treatment and disposal facilities which are still missing in the SWM chains are required to complement the improvement in collection and transportation of the solid waste. Due to this limitation of adequate treatment and disposal facilities, the untreated disposal amount remains status quo. This phenomenon has overloaded the dump sites with the need to extend the operational lifespan due to the absence of appropriate and costeffective alternatives to treat the waste. With only ten (10) sanitary landfills and 156 dump sites, the issues of environmental pollution and degradation continue despite Act 672 being in force and the government has to identify suitable treatment and disposal technologies to curb with the problems.

Despite the significant improvement in the quality of SWM services after the privatization as reported by PPSPPA in their annual report
2016, the overall SWM is not sustainable due to the substantial increase in cost. According to the annual report 2016 from PPSPPA, the government had spent RM1.86 billion in 2016 to manage the solid waste, $68.3 \%$ higher than the initial budget of RM1.105 billion. With a significantly low recycling rate at only $21 \%$ and nonavailability of proper treatment and disposal facilities, this makes the current SWM practices are not sustainable and tend to fail in the long run. Performance Management and Delivery Unit (2015) highlighted six (6) overarching issues related to the SWM industry that requires urgent attention from the government. These include (1) several gaps in existing policies, guidelines and standards hindering the actual implementations; (2) inadequate resources mainly on the technical expertise and skilled manpower; (3) insufficient fund and mismatch between revenue and cost; (4) inadequate waste facilities to cater for waste treatment and disposal; (5) inadequate data to support the implementation; and (6) unregulated and unmonitored recyclables market. Malaysia has developed his future SWM business model to achieve sustainability (Figure 8 ).

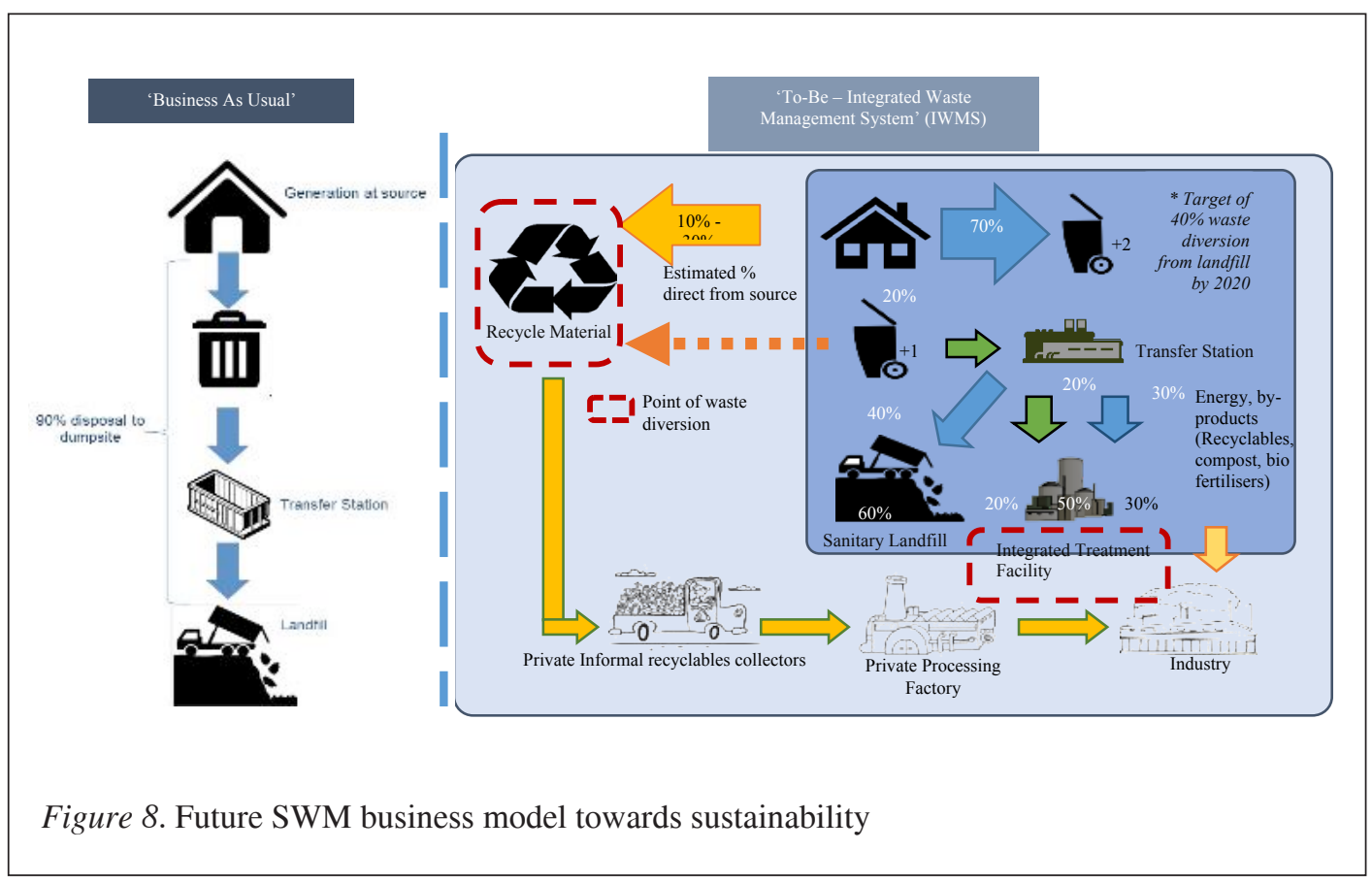


With limited educational and awareness campaigns and non-availability of suitable policies and legislation and institutional frameworks, the aims to inculcate the cleanliness and $3 \mathrm{R}$ culture among the public may take a longer time than expected which may go beyond 2020. The CE implementation which is based on the integrated SWM that focused on the concept "from cradle to cradle" would have the moderating effect on the strategy use. Its adoption into the system alongside with suitable waste to energy (WTE) technology is the best approach to develop a sustainable SWM system. WTE technology can produce renewable energy that can be derived from solid waste to mitigate GHG emissions in an economically feasible manner and at the same time provides a financial return to the economy. These strategic approaches will be the primary anchor for this study to intervene in the relationship between the variables.

In many developed countries, the process towards SD requires a strong support from the government, public and other stakeholders. The government needs to drive holistic transformation programs to ensure that $\mathrm{CE}$ is becoming a national policy that will be vigorously upheld by every level in the government and the societies. The government needs to develop a suitable framework and key enablers to drive the transformation towards a $\mathrm{CE}$ which includes (1) government political will to establish and enforce related policies, institutional and legislation structure; (2) acquiring expertise and suitable technologies; (3) stakeholders engagement and education towards behavioral changes; (4) to develop the viable market for secondary raw materials; (5) waste optimization and minimization; (6) financial support; and (7) reliable data management. These are the prerequisite enablers to ensure the successful transformation of CE that works on the closed loop approach.

A set of key indicators is another critical parameter to guide the implementation towards achieving the desired objectives within an agreed timeframe. The key indicators will include (1) waste generation growth; (2) recycling rate; (3) waste diversion; (4) GHG emissions and carbon footprints; (5) green products and services; (6) Renewable Energy; (7) eco-projects; (8) resource productivity; (9) domestic material consumption per capita; (10) employment in the CE. Based on the key enablers and critical indicators set for the adoption process of a $\mathrm{CE}$, the government would be able to develop realistic targets to cater for short, medium and long-term goals. Thus, this paper needs to deeply understand the full perspective related to a $\mathrm{CE}$ to be able to provide the conclusion as well as policy recommendations for CE's future planning and improvement in Malaysia. In short, adoption of CE will pave the way for a holistic, integrated, cost-effective and sustainable SWM system in Malaysia.

\section{Research Method}

This study employed a literature review to identify relevant practices of a circular business model that can potentially be adopted, an LC analysis methodology to assess the environmental impacts of a product and a waste characteristic and its composition study to determine the waste fraction and the available amount of energy in solid waste. This study applied a quantitative research method. The data sampling for LC will be collected only for recyclables materials in the household waste sector. The data on waste compositions, characteristics, and $3 \mathrm{R}$ practices will be collected and divided according to (1) geographical distribution; (2) regional distribution; (3) size variation; (4) socio-economic; (5) sectorial diversity; and (6) rural and urban areas (Figure 9). The analysis of the waste will be carried out using the sampling technique as per draft Malaysian Standard 10Z011R0 (2011). All other data will be collected from the scientific works 
of literature, existing databases, observations on the phenomenon, and structured interviews with relevant policymakers, and a set of questionnaires applied to selective stakeholders. Descriptive and inferential statistical methods were used to conclude.

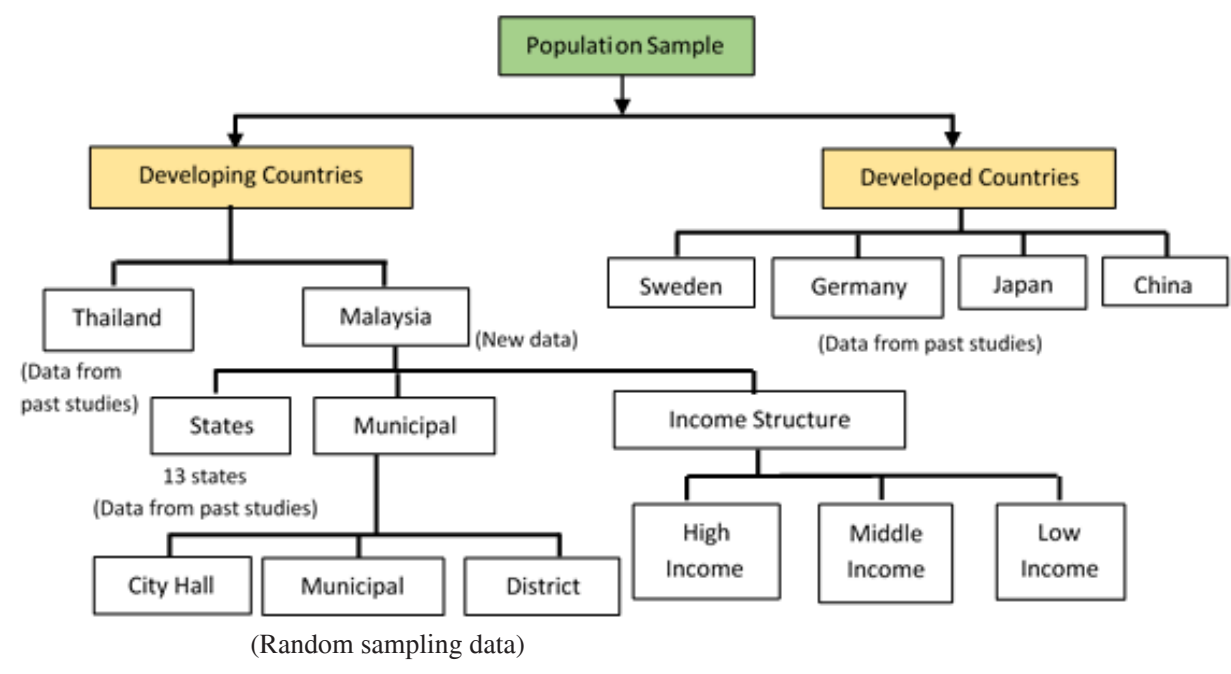

Figure 9. Data collection for waste sampling categories

Past studies refer to experimental research as the most valid approach to the solution of solving the SWM problems. The empirical research design method is also generally regarded as the most sophisticated research method for the testing of hypotheses. Sample and sampling technique used as per draft Malaysian Standard 10Z011R0 (2011): since the population of the study is large covering the 12 local authorities in Kedah State; the study was divided into several categories. Due to the importance to collect the right information on waste generation, composition and characteristic to ascertain the full value in waste, the actual weighing of waste (wet and dry) were carried out as below:

\section{Category 1 \& 2 - Waste Generation and Waste Composition}

- $\quad$ Collection of waste generation data (historical data from literature) from one sample each to provide benchmarking in term of waste generation per capita for two (2) developing and two (2) developed countries, seven (7) states in Malaysia and 12 municipalities in Kedah.

- Collection of waste sampling from household based on income groups (Kedah).

- Collection of waste sampling for each income group - high income, medium, and low-income group (Kedah).

- $\quad$ Note: Load Account Analysis (LCA) which is based on the amount of waste discarded (source) and disposed of (landfills) was used to identify the amount of waste generated.

- $\quad$ Sampling data: - minimum two (2) samples.

Category 3 - Waste Characteristics (Data collection samples - same areas as above) 
In term of the emission and energy benefit from solid waste, data such as population, waste generation, composition and its characteristics were collected. The moisture content was analyzed using proximate (wet) and elemental (dry) analysis. The energy conversion model and carbon emission model were used to calculate the emission benefit and energy potential from incineration and landfill gas recovery system. The amount of GHG emission and water pollution were analyzed to indicate the level of environmental degradation using an intergovernmental panel on Climate Change (IPCC) analysis. Despite some underlying problems and challenges, LC assessment is a decision-support tool that, through its holistic perspective in quantifying environmental impacts, has been demonstrated to provide valuable inputs to identify appropriate lifespan of each product. The assessment of energy demand indicators was in this context regarded as an impact assessment because of its ability to serve as an acceptable proxy for some impact categories. Huijbregts et al. (2006) showed a relatively good correlation of cumulative energy demand scores with stratospheric ozone depletion and resource depletion indicator scores for waste treatment processes. The results of the emission quality and the economic benefit were derived to ascertain the economic value.

\section{Category $4-3 R$ practices}

Survey and observation on $3 R$ initiatives were used to gauge the implementation of policy and legislation, education and awareness level on the 3R concept.

\section{Analyzing Data}

Hypotheses testing, ANOVA, Correlation Analysis, Pearson Correlation Analysis and Multiple Regression Analysis were used to examine all the hypothesis in the research questions.

\section{Findings}

This study proved that the current throwaway practice of an LE model is ineffective and unsustainable. This phenomenon indicated a strong correlation between the economic development that influenced the exponential increased of waste generation. At a Gross Domestic Product (GDP) of $4.2 \%$ with 31.9 million populations and $76 \%$ rural-urban migrations, the amount of solid waste generation in Malaysia has reached 37,000 tons per day in 2016 at an increasing rate of $4 \%$ per annum. The amount of waste generation per capita has significantly increased from 0.8 in 2005 to 1.17 in 2016, and the generation of solid waste has increased by more than $91 \%$ for the past ten (10) years. SWM in Malaysia is becoming more critical due to the absence of proper treatment, recovery and disposal facilities couple with a low recycling rate of only $21 \%$. Non-availability of a sustainable SWM system in place has caused severe environmental pollution and posed significant financial impact at RM1.86 billion for the government to manage the waste.

Despite the enforcement of the Act 672 in September 2011, the overall scenario remains unchanged with minimum impact on the waste minimization, treatment, and recovery. The policy implementation on SWM does not go as planned (Abas \& Wee, 2014). Malaysia lacks on the political will to enforce the policies such as clause 101 Reduction, Reuse, and Recycling of controlled solid waste and clause 102 Take Back System and Deposit Refund System which were developed under the Act 672 to address the 3R strategy (Moh \& Abd Manaf, 2014). A waste composition study carried out on the discarded waste at the household bin point indicated that society is still not aware of the enforcement of SAS with $32 \%$ of the waste inside the bin are consisted of recyclable materials. Moh and Abd Manaf (2017) stated that the biggest challenge to implement SAS and recycling practice is the public attitude towards making the source separation and recycling as a habit. Majority of Malaysians do not interpret their awareness and knowledge into practice, and they failed to relate the benefit of implementing SAS and recycling and also the consequences for the ignorance. 
Therefore, the government needs to transform from the current LE practice to the CE business model that treats waste as valuable resources and reap the potential economic benefit from the useful materials and the potential energy emission derived from the solid waste. By ensuring there is no leakage of recyclable materials to the informal sectors, the government could anticipate an income from waste amounting to RM1.4 billion per year derived from the $22 \%$ of recyclables items. Proper planning on the investment of the WTE technology and safely engineered landfills will further enhance the renewable energy emission from solid waste. Tan et al. (2014) indicated that the integration of landfill gas (LFG) recovery systems and waste incinerator as the WTE strategies show the highest economic benefit with optimal GHG mitigation and energy potential. The combination of $64 \%$ sanitary landfills and $36 \%$ incinerations was theoretically proven to be the optimal combination to have lower GHG emission at 0.634 ton of $\mathrm{CO} 2 /$ ton of solid waste as compared to the current practices of $100 \%$ landfills without LFG recovery at 1.1 ton of $\mathrm{CO} 2 /$ ton of solid waste. This arrangement would optimize the cost with a total net profit of USD40.1/ton of solid waste. The current business as usual practices indicated the highest GHG emission at 1.1 ton of $\mathrm{CO} 2 /$ ton of solid waste with a negative net profit of USD -15/ ton of solid waste. The utilization of renewable energy could save the country of USD1.32 billion with $5 \%$ energy mix over a period of five (5) years and should contribute towards mitigating the effects of climate change (Hashim \& Ho, 2011).

Applying to the vision of ISWA that earth where no waste exists and the adoption of CE practices have proven to ensure a full recovery of the economic values from waste. The adoption of CE practices have enhanced the waste minimization and efficiently utilizes the resources to attain the maximum value in solid waste and proves that SWM is financially capable of being selfsustaining and would alleviate the government financial burden. Besides the economic benefits, the successful implementation of the CE managed to harmonize the environment and improve the quality of life. Realistically, the government should have the short term which aims to divert $40 \%$ of waste from landfill and to achieve $30 \%$ recycling rate by 2020 through the adoption of CE. Findings from this study endeavor to provide guidelines for Malaysia to realize a successful transformation towards a $\mathrm{CE}$ that can maximize the economic return from waste, reduce the cost, protect the environment and improve the quality of life for the people. The adoption of CE can pave the way for a more realistic roadmap towards sustainability.

\section{Conclusion}

CE embraces the economic strategy to promote the SD of economy and society and to achieve sustainable environmental protection. The CE concept has been proven to develop a sustainable SWM system in many developed countries successfully, and it is time for Malaysia to adopt and customize the idea to meet our needs. The adoption of CE couple with the right technology for waste treatment, recovery and disposal facilities will ensure a sustainable SWM system in Malaysia. RM1.4 billion that is derived solely from the recovery of valuable materials in the waste can finance approximately $75.3 \%$ of the totals SWM cost of RM1.86 billion; this will assist to alleviate the government financial burden. Therefore, in the spirit to achieve the aspiration, the government must treat a $\mathrm{CE}$ as a National Policy that will be vigorously upheld by every level in the government and societies. The enactment of the law should involve the role of federal and state government, local authorities, public, producers and whoever that will generate the solid waste (Abas \& Wee, 2014). In fact, the successful adoption of the CE would provide a very significant contribution to the economy, environment, and the community. Malaysia would be able to develop and spur his economy without imposing any adverse impacts on the 
environment, preserve the natural resources and at the same time provides healthy and conducive living to the society. The approach will pave the way for Malaysia to realize his dream to become a developed nation.

\section{References}

Act 672. Solid Waste and Public Cleansing Management Act 2007 (Act 672) (2007). Malaysia.

Abas, M. A., \& Wee, S. T. (2014). The issues of policy implementation on solid waste management in Malaysia. International Journal of Conceptions on Management and Social Sciences, 2(3), 12-17.

Badgie,D.,Samah,M.A.A.,Manaf,L.A.,\&Muda, A. B. (2012). Assessment of municipal solid waste composition in Malaysia: Management, practice, and challenges. Polish Journal of Environmental Studies, 21(3), 539-547. http://doi. org/10.1177/0734242X04047661

Boulding, K.E. (1966). The economics of the coming spaceship earth. environmental quality in a growing economy, resources for the future, Washington, D.C.

Draft Malaysian Standard 10Z011R0 (2011). Guidelines for Sampling of Household Solid Waste - Composition and Characterization Analysis. SIRIM Berhad.

Ellen MacArthur Foundation. (2013). Towards the circular economy. Cowes, UK: Ellen MacArthur Foundation.

Emas, R. (2015). The concept of sustainable development: definition and defining principles. Brief for GSDR, 1-3. https:// doi.org/10.1016/j.marpol.2014.01.019

Ministry of Housing and Local Government Malaysia. (August 2005). National Strategic Plan for Solid Waste Management. Ministry of Housing and Local Government. Malaysia.

Hashim, H., \& Ho, W. S. (2011). Renewable energy policies and initiatives for a sustainable energy future in Malaysia. Renewable and Sustainable Energy Reviews, 15(9), 4780-4787. http://doi. org/10.1016/j.rser.2011.07.073

Hoornweg, D., \& Bhada-Tata, P. (2012). A Global Review of Solid Waste Management. World Bank Urban Development Series Knowledge Papers. Retrieved from https://openknowledge. worldbank.org/handle/10986/17388

Huijbregts, M. A., Rombouts, L. J., Hellweg, S., Frischknecht, R., Hendriks, A. J., van de Meent, D., ... \& Struijs, J. (2006). Is cumulative fossil energy demand a useful indicator for the environmental performance of products? Environmental Science and Technology. https://doi. org/10.1021/es051689g

International Solid Waste Association. (2015). Circular economy: Resource management. International Solid Waste Association.

Jabatan Pengurusan Sisa Pepejal Negara, J. (2013). Survey on solid waste composition, characteristics \& existing practice of solid waste recycling in Malaysia. Jabatan Pengurusan Sisa Pepejal Negara. Retrieved from http:// jpspn.kpkt.gov.my/resources/index/ user_1/Sumber_Rujukan/kajian/Final_ Report_REVz.pdf

Johari, A., Alkali, H., Hashim, H., Ahmed, S. I., \& Mat, R. (2014). Municipal solid waste management and potential revenue from recycling in Malaysia. Modern Applied Science, 8(4), 37-49. http://doi. org/10.5539/mas.v8n4p37

Karak, T., Bhagat, R. M., \& Bhattacharyya, P. (2012). Municipal solid waste generation, composition, and management: The world scenario. Critical Reviews in Environmental Science and Technology, 42(15), 1509-1630.

Lewandowski, M. (2016). Designing the business models for circular economytowards the conceptual framework. Sustainability (Switzerland), 8(1), 1-28. http://doi.org/10.3390/su8010043 
Manaf, L. A., Samah, M. A. A., \& Zukki, N. I. M. (2009). Municipal solid waste management in Malaysia: Practices and challenges. Waste Management, 29(11), 2902-2906. http://doi.org/10.1016/j. wasman.2008.07.015

Moh, Y. C., \& Abd Manaf, L. (2014). Overview of household solid waste recycling policy status and challenges in Malaysia. Resources, Conservation and Recycling, 82(July 2014), 50-61. http://doi. org/10.1016/j.resconrec.2013.11.004

Moh, Y. C., \& Abd Manaf, L. (2017). Solid waste management transformation and future challenges of source separation and recycling practice in Malaysia. Resources, Conservation and Recycling. http://doi. org/10.1016/j.resconrec.2016.09

Mohammad. (2017, September). The Paradigm Shift: Adoption of Circular Economy for a Sustainable Solid Waste Management in Malaysia. Paper presented at the International Solid Waste Association World Congress, Baltimore, United States of America.

Perbadanan Pengurusan Sisa Pepejal Dan Pembersihan Awam. (2016). Lapuran Tahunan 2016. Perbadanan Pengurusan Sisa Pepejal Dan Pembersihan Awam. Malaysia.

Performance Management and Delivery Unit. (2015). Solid Waste Management Final Lab 2015 (Draft Final). Jabatan Perdana Menteri. Malaysia.
Periathamby, A., Hamid, F. S., \& Khidzir, K. (2009). Evolution of solid waste management in Malaysia: Impacts and implications of the solid waste bill, 2007. Journal of Material Cycles and Waste Management, 11(2), 96-103. http://doi. org/10.1007/s10163-008-0231-3

Schroeder, P. (2018). the relevance of circular economy practices to the sustainable development goals. Research and Analysis, 23(1), http://doi.org/10.1111/ jiec. 12732

Scott, J.T. The sustainable business a practitioner's guide to achieving longterm profitability and competitiveness, 2nd ed.; Greenleaf Publishing: Sheffield, UK, 2015.

Tan, S. T., Hashim, H., Lim, J. S., Ho, W. S., Lee, C. T., \& Yan, J. (2014). Energy and emissions benefits of renewable energy derived from municipal solid waste: analysis of a low carbon scenario in Malaysia. Applied Energy, 136, 797-804.

Waste, M. S. (2015). Global waste management outlook, (September), 4-7. http://doi. org/10.1177/0734242X15616055

WBCSD. (2016). CEO guide to circular economy. C2C Bizz, 2(3), 1-50. 